\title{
ADSORPTION OF CHROMATE/ORGANIC-ACID \\ MIXTURES IN AQUIFER MATERIALS
}

\author{
Technical Progress Report \\ 1 July 1990 - 30 June 1991
}

Report No. DOE-ER/60845-2

William Fish and Carl D. Palmer

Department of Environmental Science \& Engineering

Oregon Graduate Institute

Beaverton, Oregon 97006

15 July 1991

\section{DISCLAIMER}

This report was prepared as an account of work sponsored by the United States Government. Neither the United States ncr any agency thereof, nor any of their employees, makes any warranty, express or implied, or assumes any legal liability or responsibility for the accuiacy, completeness, or usefulness of any information, apparatus, product, or process disclosed, or represents that its use would not infringe privately owned rights. Reference herein to any specific commercial product, process, or service by trade name, mark, manufacturer, or otherwise, does not necessarily constitute or imply its endorsement, recommendation, or favoring by the United States Government or any agency thereof. The views and opinions of the authors expressed herein do not necessarily state or reflect those of the United States Government or any agency thereof. 
Chromate and organic acids are widespread contaminants at DOE contamination sites. These anionic compounds are often found as co-contaminants, along with other anions such as nitrate, cyanide, and fluoride. The mobility of anionic contaminants depends strongly on the extent of adsorption, which occurs primarily to positively charged oxide minerals. Unfortunately, most studies of anion adsorption were conducted on single adsorbates and there has been little examination of the interactive effects of combinations of auionic adsorbates. Furthermore, the adsorptive behavior of many organic acids, even as isolated adsorbates, is poorly understood. This project addresses these problems by elucidating the binding mechanisms of organic acids and the competitive interactions of chromate and selected organic acids on mineral surfaces. A combination of wer-chemical and spectroscopic methods are being used.

The second year of the project has focused on the competitive adsorptive interactions of oxalate, one of the most important organic acids at DOE sites and in natural soils, and chromate, a highly toxic and widespread contaminant. The results indicate that chromate will generally "outcompete" oxalate for available surface binding sites by virtue of the greater stability of the chromate surface complexes. Chromate binding can significantly lower the extent of oxalate binding. However, when solution concentrations of oxalate/chromate are relatively high, the adsorption of chromate also may be repressed. The results for binary-adsorbate (anion competition) experiments could be generally well modelled by a surface complexation model that was parameterized for the simple, single-adsorbate data. This finding is very encouraging because it indicates that many of the complex mixtures of ions found in nature and at waste sites may be amenable to predictive modeling.

Our work with competing anions has also led to novel research in the area of ligand-promoted mineral dissolution. In single-adsorbate systems, surface speciation and solution concentrations inherencly co-vary. We have celaxed this experimental limitation by using two competing adsorbates: one which is "dissolution promoting" (oxalate) and one which is "non-dissolution promoting" (chromate). Binary systems of chromate and oxalate allow us to vary the surface concentration and solution concentration of the oxalate virtually independently. We executed a matrix of binarr-adsorbate experiments for a range of solution and surface concentrations of oxalate. The established formulation of dissolution rate as proportional to surface-bound oxalate is correct, but incomplete. The oxalate solution concentration is equally critical in the dissolution rate law when ligand surface coverage is ralatively low. Previous studies did not Elucidate this aspect of the rate law because they could not simultaneously set high levels of solution oxalate and low surface coverages of oxalate.

We have extensively refined in-situ Fourier transform infrared (FTIR) spectroscopic techniques and have used them to quantify the adsorptive functional groups in structurally heterogeneous soil organic matter. The initial work in this area is now complete: in future research, these techniques will be applied to studies of functional groups in other heterogeneous soil systems.

In the remaining 6-months of the project, we will focus on the interactions of chromate and organic acids, applying a combination of conventional titration methods and ir-situ FTIR surface spectroscopy. Experimental procedures are nc:: ircluding studies of natural aquifer materials found at DOE sites. 
I. OVERVIEW . . . . . . . . . . . . . . . . . . . . . . . . . . . . . . . . . . . 1

I.A. Specific Project Objectives . . . . . . . . . . . . . . . . . . . . . . . . 1

I.B. Scientific Issues Currently Addresses . . . . . . . . . . . . . 1

I.C. Inportance of Solving the Problem . . . . . . . . . . . . . . . 3

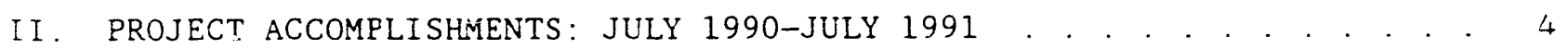

II.A. Summary of Project Products . . . . . . . . . . . . . . . . . . . . . . . 4

II.B. Synopsis of Research Results . . . . . . . . . . . . . . . . . . . 4

III. PLANS FOR THE NEXT REPORTING PERIOD . . . . . . . . . . . . . . . . . . . 21

IV. APPENDIX: The Variable Nature of Humic Carboxyl Content Measurement

(Environ. Sci. Technol. 25:232-240) . . . . . . . . . . . . . . 22 


\section{LIST OF FIGURES}

Page

Eigure 1. Adsorption of chromate as a function of solution $\mathrm{pH} . . .4 . \quad . \quad 8$

Figure 2. Adsorption of oxalate as a function of solution $\mathrm{pH} . . . \quad \cdot . \quad . \quad 10$

Figure 3. Adsorption isotherm for chromate . . . . . . . . . . . . . . . 11

Figure 4. Adsorption isotherm for oxalate . . . . . . . . . . . . . . . . 12

Figure 5. Adsorption $\mathrm{pH}$ edges of chromate as a function of chromate. . . 13

Figure 6. Adsorption $\mathrm{pH}$ edges of oxalate as a function of oxalate . . . . 14

Figure 7. Binary-adsorbate experiments:

$[\mathrm{Ox}]=10 \mathrm{uM},[\mathrm{Cr}]=10 \mathrm{uM} ;[\mathrm{Ox}]=50 \mathrm{uM},[\mathrm{Cr}]=50 \mathrm{uM} . .15$

Figure 8. Binary-adsorbate experiments:

$[\mathrm{Ox}]=800 \mathrm{uM},[\mathrm{Cr} j=10 \mathrm{uM} ;[\mathrm{Ox}]=800 \mathrm{uM},[\mathrm{Cr}]=50 \mathrm{uM} . . .16$

Figure 9. Binary-adsorbate experiments:

$[\mathrm{Ox}]=800 \mathrm{uM},[\mathrm{Cr}]=200 \mathrm{uM} ;[\mathrm{Ox}]=10 \mathrm{uM},[\mathrm{Cr}]=800 \mathrm{uM} . .17$

Figure 10. Total adsorption of oxalate or chromate in binary system . . . 18

Figure 11. Effect of oxalic acid on goethite dissolution rate . . . . . 19

Eigure 12. Effect of $\mathrm{Cr}$ adsorption on oxclate-promoted dissolution . . . . 20 


\section{OVERVIEW}

\section{I.A. Specific Project Objectives}

The overall objective of this project is to develop a fuller understanding of the interactions of mixtures of anionic co-contaminants with oxide-mineral surfaces. Our specific focus is on the competitive interactions of chromate and oxalic acid on ferric oxyhydroxide and on natural aquifer materials. Chromate and oxalate are of practical interest as widespread contaminants at many DOE facilities. However, these anions also are excellent model adsorbates for Elucidating fundamental aspects of ionic adsorption processes, particularly with respect to organic acids.

The proposed research is being executed in two stages. In the first stage we quantifyied the adsorption characteristics of chromate and oxalic acid, individually and in combinations representative of mixtures found at DOE sites. A pure, well characterized sorbent was used so that underlying mechanisms of adsorption and sorptive competition could be clearly elucidated.

The second stage generalizes the adsorption methods of the first stage to natural aquifer materials from selected DOE sites. Site materials chosen for this project have specific adsorptive phases of interest. Selected experiments from the first stage will be repeated on these aquifer materials to assess the applicability of current models in predicting multiple-anion adsorption in soils and aquifers. Criteria for applying pure-phase adsorption data to natural aquifer matrices will be developed.

\section{B. Scientific Issues Currently Adidressed}

The research completed in the past year was essentially identical to the work proposed in the continuation proposal for the year. No significant deviations from our objectives were necessitated, nor are any substantial deviations planned in the final six months of the project. A summary of the scientific issues we are currently addressing is presented here.

The adsorption of anionic compounds appear to be capable of being modeled by somewhat simpler methods than do metal ions. Unlike metals, anions generally reach a well defined site saturation on soils and model oxide surfaces. Anions are less likely to form solid-solutions at surfaces than are metals, so straightforward surface complexation models give generally good results. One scientific issue we are addressing is the applicability of this apparently straightforward modeling approach to mixtures of adsorbing anions.

We hypothesize that adsorption of mixtures on very homogeneous mineral phases can be modeled by a linear combination of anion adsorption reactions, but as surfaces become more heterogeneous, we expect the extent of anion interaction at the surface to decline. That is, the competition of anions for a homogeneous surface should be a simple mass law effect, whereas with increasing site heterogeneity, the inter-ion competition should diminish. We are directly testing these hypotheses by experiments using purified goethite (a nearly homogeneous adsorbent), a series of goethite-rich silica sands from the Savannah River DOE site (moderately homogeneous natural adsorbents) and selected complex ferricoxide/clay-mineral/aluminum-oxide subsoils taken from the Hanford or other DOE 
sites (highly heterogeneous natural adsorbents). A corollary area of research is the use of binary adsorbate systems to probe the details of the roles played by adsorbed and solution ions in ligand-promoted dissolution of oxide minerals.

A second, related issue on which we focus is the extent to which heterogeneous adsorbents can be characterized by conventional wet-chemical analyses, such as titrations. Research on the binding properties of naturally heterogeneous humic materials (natural organic matter) has proven to be a useful paradigm for this question. A number of previous studies of humic matter have discussed the limitations of titrations in identifying particular functional groups or quantifying particular ranges of binding-site energies for such materials. In this project we are developing a rigorous analysis of these limitations, based on experimental and theoretical considerations. The impossibility of unambiguous site definition in heterogeneous adsorbents by indirect (titration) methods leads logically to the need for direct spectroscopic determination of binding sites.

A third scientific issue addressed by this project is the development and use of infrared spectroscopic methods for identifying and quantifying binding functionalities. Building on previous and on-going research funded by DOE (the Anderson group at Wisconsin; Marley $\&$ Gaffney at Argonne) we are utilizing modern Fourier-transform IR (FTIR) spectroscopy with a circular internal reflectance (CIR) cell to quantitatively measure surface species in aqueous suspension. Anderson's work with ethite and Marley's work with humic materials clearly show the power of this technique. We are taking this spectroscopic method in a somewhat different direction by testing its utility for analyzing functional groups in heterogenous natural materials. Our initial work with heterogeneous humic matter has allowed us to define improved techniques for quantitative handling of complex FTIR data. We plan to extend our ability to accurately measure ionized and un-ionized surface functional groups on humic materials into research on the binding sites of natural mineral assemblages in DOE site samples.

For our studies of adsorption from binary mixtures of anions we use batch methods in which chemical equilibrium is assumed. As mentioned above, initial efforts have centered on a well defined iron oxide, but we are branching into the use of selected natural materials from DOE sites. In keeping with the overall goals of the Subsurface Science Program our focus is on relatively dilute systems which are representative of contaminants after they have reached the soil or aquifer. We have chosen anions that are of specific relevance to DOE site, but which are also of general relevance to the field of subsurface science. These adsurbates have been chosen in specific combinations that we believe will yield the greatest amount of fundamental information about adsorption and related processes in the subsurface.

For the experiments with natural aquifer materials, we are utilizing a set of samples obtained from several DOE sites including Hanford and Savannah River Site samples are being selected in cooperation with other Subsurface Science Program (SSP) investigators to minimize overlap of effort and maximize the database for these site materials. For example, Zachara and co-workers at PNL have completed a significant characterization of certain site materials. The SSPCoupled Processes project led by Girvin and Bolton is another program using these materials. By using materials selected from among these samples, we eliminate the time and expense of identifying mineral composition and other basic characteristics. Our work on adsorption will benefit from comparison with 
previous and on-going research using those materials. Conversely, other DOE researchers will benefit from the information on anion binding and the spectroscopic information we obtain in our studies.

The theories used to explain and unify this research are primarily those of the highly successful surface complexation model of ionic adsorption. This model describes anion adsorption by specific chemical complex-formation at the oxidewater interface, as modified by the effects of Coulombic charge generated by the ionization of acidic surface groups. This model is strictly applicable only at equilibrium, so we have made the necessary measurements to verify this assumption. for our conditions. We have used extensions of surface complexation theory to interpret certain kinetic phenomena, specifically, ligand-promoted dissolution of the oxide surface.

\section{I.C. Importance of Solving the Problem}

Predicting the transport and fate of ionic contaminants in soils and groundwater is a central problem in both the assessment and remediation of waste sites. Assessment of the severity and the possible human or ecological impacts of site contamination by ionic constituents requires accurate models of ionic adsorption onto soils and sediments. Planning and implementing a realistic and cost-effective site-remediation scheme also requires accurate predictions of adsorption. For example, the efficacy of pump-and-treat cleanup methods depends strongly on the concentration of contaminant in the mobile (aqueous) phase. For these reasons it is essential that current understanding of ionic adsorption and the methods of modeling such adsorption be improved. There is little data with which to evaluate the suitability of current models for the complex mixtures of ions encountered in the environment. Because most waste sites contain a plethora of different contaminants, we believe that multiple-adsorbate systems must be a special focus of research.

Anions may be a somewhat more tractable subject than metals for representation by surface complexation models. We hypothesize that anions offer the greatest likelihood for the successful application of surface complexation models to complex soil or aquifer systems. Our results indicate that, for relatively homogeneous surfaces, modeling of multiple-adsorbate systems may be achieved by computing the simple equilibrium among independent surface reactions. If these results are found to be generally applicable, then any arbitrary mixture of anions can be successfully modeled (in principle) on the basis of tabulated adsorption parameters for individual, single-adsorbate reactions.

The related scierific questions we are asking (dissolution kinetics, binding site analysis, and surface spectroscopy) all contribute to the overall picture of the behavior of mixtures of anions in complex natural media. The longcerm stability of adsorptive phases is affectud by rate at which they dissolve, the ability to model systems more heterngeneous than those discussed above depends on site analysis, which in turn is most likely to be effective via spectroscopic techniques. Although this brief review of activities in FY 1991 focuses on our short-term scientific goals, the long-range goal of effective modeling of contaminant trarisport and fate in complex natural systems hinges on obtaining answers to these diverse but closely interrelated questions. 
II. PROJECT ACCOMPLISHMENTS: JULY 1990 - JUNE 1991

II.A. Summary of Project Products

In the past year the research conducted under this grant generated a refereed publication, two presentations at national scientific society meetings, a graduate student paper award, and the preparation of two manuscripts which will be soon submitted for publication.

- The results of the chromate/oxalate interaction experiments for goethite are now complete. A paper describing the results of single-adsorbate experiments and the associated modeling techniques is in preparation. a companion paper describe the extension of this work for binaryadsorbate mixtures. These two papers will be submitted together as a two-article series to Environmental Science \& Technology in late summer 1991.

- These findings on chromate/oxalate interactions were presented at the Surface Chemistry Symposium at the American Geophysical Union Fall Meeting, San Francisco, December 1990.

- A manuscript on our work detailing the practical and theoretical limitations on titration methods of binding site identification received a 1990 Graduate ztudent Paper Award from the Environmental Chemistry Division of the American Chemical Society. The manuscript was subsequently accepted by Environ. Sci. \& Technol., and was published in the February 1991 issue (see Appendix).

- The work described in the ES\&T paper was presented at the 200th National Meeting of the American Chemical Society in Washington, D.C., August 1990.

- The investigations of oxalate-mediated dissolution in mixtures with chromate are described in a manuscript currently in preparation for submission to J. Coll. Int. Sci. The principle investigator (W. Fish) has been invited by Prof. W. Stumm to present these results in a seminar at the Swiss Federal Institute for Water Resources (EAWAG) in August 1991.

- Investigations with in situ FT-IR were completed and have delineated the practical strengths and weaknesses of this method for characterizing natural heterogeneous sorbents. We have identified several serious, and hitherto unpublished, problems with the method. A two-article series articulating these problems, our solutions to these problems, and some practical applications on the method will soon be submitted to Geochimica Cosmochimica Acta.

\section{II.B. Sunopsis ot Research Results}

The adsorptive behavior of chromate and oxalic acid onto goethite $(\alpha-\mathrm{FeOOH})$ were identified in conventional single-adsorbate and in novel binary-adsorbate batch experiments. Adsorption in both types of experiments was quantified as a 
function of $\mathrm{pH}$, adsorbate concentration, and background electrolyte concentration. Single adsorbate experiments for both ions confirmed the characteristic anionic adsorption pH-edges in which adsorption is negligible at $\mathrm{pH}$ values above the point of zero charge (PZC) but increases at more acidic $\mathrm{pH}$ values, reaching maximum adsorption near the $\mathrm{pH}$ corresponding to the second proton-ionization constants of these diprotic acids $\left(\mathrm{pk}_{\mathrm{a} 2} \approx 4.1\right.$ for oxalic acid, 6.8 for chromate). These data could be accurately modelled using a diffuse-layer version of the surface complexation model (the Diffuse-Layer Model or DLM), as shown in Figs. 1 and 2 .

Chromate exhibited stronger adsorption to goethite than oxalate. The adsorption of both ions showed Langmuir-type adsorption, typical for anions, in which the concentration of surface-bound ions was proportional to the concentration of ions in solution, up to a saturable total surface capacity (Figs. 3 and 4). The specific surface capacity of goethite for chromate was approximately $160 \mu$ moles $/ g$, for oxalic acid the specific surface capaci.ty was somewhat less at approximately $125 \mu$ moles $/ \mathrm{g}$. The difference is probably due to the smaller size of the chromate ion. The adsorption of both ions was diminished by increasing concentrations of background electrolyte. The effect of background electrolyte was slightly greater for oxalate than for chromate (Figs. 5 and 6).

Binary adsorbate experiments revealed the extent of competition between these ions for surface binding sites (Figs. 7a,b). When both ions were present at comparatively low total concentrations, leading to surface coverage for either ion of $<58$ of capacity, there was no significant change in the adsorption pH-edge of either ion; adsorption at low coverage was essentially independent and noncompetitive. If chromate was kept at low concentrations but oxalate was added at a level sufficient to saturate the surface sites, the adsorption of chromate was somewhat inhibited, but the "excess" capacity of the surface for chromate in comparison to oxalate appears to allow most of the chromate to remain bound (Figs. $8 a, b$ ). The interaction between ions at the surface is relatively weak and a great excess of oxalate is necessary to substantially desorb the chromate (Fig $9 a)$. However, when oxalate concentrations were relatively low and chromate was added to the point of site saturation, the oxalate speciation changed from -100 o adsorbed at $\mathrm{pH} 6$ to $<50 \mathrm{z}$ adsorbed. The stronger intrinsic binding of chromate compared to oxalate leads to a high degree of interaction between the two ions at the goethite surface.

Thus, significant surface interactions (site competition) occurred only when the total coverage of the surface approached saturation, and was most pronounced when chromate was in excess of oxalate, as would be expected from a simple thermodynamic computation. These results indicate that binary mixtures of anions on a homogeneous surface such as goethite can be modeled using a fairly simple combination of the data from single-adsorbate experiments, after accounting for differences in the total capacity of the surface for each ion. The competitive interactions of chromate and oxalate are summarized in Fig. 10.

In addition to the batch equilibrium adsorption experiments, we have conducted a several sets of experiments to examine kinetic aspects of adsorption from binary anion mixtures. In the simplest kinetic experiments we monitored the extent of oxalic acid or chromate adsorption as a function of time for various solution conditions. As is typical for most adsorption processes, we observed an initial stage of very rapid uptake followed by a somewhat prolonged period of slow uptake. We found that complete adsorption equilibrium was obtained within 
30 min for low to intermediate sorbate/sorbent ratios (up to $5.5 \times 10^{-5}$ mole adsorbate/g goethite). At higher ratios, the slow step became more pronounced and full equilibrium required 10 to $12 \mathrm{~h}$. However, additional adsorption after 30 min equilibration was always less than 58 . We found that allowing $1 \mathrm{~h}$ equilibration time for all additions gave a very satisfactory approximation of equilibrium for our conditions. These experiments also yielded estimates of adsorbate uptake rates, which may be useful in modeling aquifers under dynamic flow conditions.

A second, more complex set of kinetic experiments explored the rates of goethite dissolution induced by the surface coordination of oxalate. At $\mathrm{pH}<5$, oxalic acid can promote the dissolution of ferric oxides such as goethite. The rates are not extremely fast for the conditions we employed, but it was important to test the effect of this dissolution on our experimental systems. From the perspective of the batch equilibrium experiments, we found that goethite dissolution had no effect on the surface speciation or the solid/liquid distribution of either oxalate or chromate. Under acidic conditions in the presence of high oxalate. the goethite may dissolve, but the rate of adsorption is much faster than the dissolution rate, so the surface/solution equilibria are essentially undisturbed by the slow dissolution. This result confirmed the applicability of equilibrium models over the entire range of experimental conditions. However, dissolution-rate experiments also provided some very useful incidental information about the nature of ligand-enhanced dissolution. Although this was not one of our original research goals, we have made some significant discoveries in this area.

A set of dissolution rate experiments was conducted at $\mathrm{pH} \mathrm{4,} \mathrm{a} \mathrm{pH}$ of maximal adsorption for both oxalate and chromate, and, being the lowest $\mathrm{pH}$ in our range of interest, exhibited the fastest goethite dissolution rates. Stumm and coworkers had previously documented that oxalate adsorbed at acid pH enhances goethite dissolution, and we were able to replicate their results. We showed that chromate had no effect on goethite dissolution. Our novel results were obtained when we examined goethite dissolution in the presence of binary mixtures of oxalate and chromate. If the goethite surface sites were saturated with oxalate, the maximal dissolution rate was obtained, as expected. Ir chromate was then added to solution at a level sufficient to desorb $50 \%$ of the oxalate, the dissolution rate declined by approximately 508, in accordance with the theory of Stumm et al. that dissolution is linearly related to surface coverage. However, if ve repeated the experiment so that the initial oxalate concentration gave only 50 site coverage with no chromate added, virtually no dissolution was observed.

This apparent contradiction led us to recognize that binary systems of chromate and oxalate allow us to vary the surface concentration and solution concentration of the oxalate virtually independentiy. That is, we can fix the solution concentration of oxalate at any given level, and then independently set the surface concentration of oxalate by simply adding the appropriate amount of chromate to compete with the oxalate.

We executed a matrix of these experiments over a range of solution and surface concentrations of oxalate. We have showed that Stumm's formulation of dissolution rate as proportional to surface-bound oxalate is correct, but incomplete. The concentration of oxalate in solution is an equally critical factor in the dissolution rate when the surface coverage is relatively low. Oth $3 r$ researchers, working with only single adsorbate systems, did not previously 
elucidate this rather logical phenomenon because they could not (at low $\mathrm{pH}$ ) simultaneously set a high level of solution oxalate and a low surface coverage of oxalate.

With single adsorbate systems, surface concentrations and solution concentrations inherently co-vary. One is restricted to conditions of either high surface coverage with excess ligand in solution, or else low surface coverage with immeasurable amounts of ligand in solution. Our experimental results using competitive binary systems in which one ligand is "non-dissolving" (i.e., chromate) allow a much more compete image of ligand-promoted dissolution to be developed. These results currently are being prepared for publication. In addition to this very interesting exploration of the fundamental aspects of oxide dissolution, our binary-adsorbate dissolution experiments have a very practical dimension in understanding the stability of oxide minerals in aquifers exposed to mixtures of dissolution-promoting and non-promoting ligands, such as expected at many of the DOE sites. 


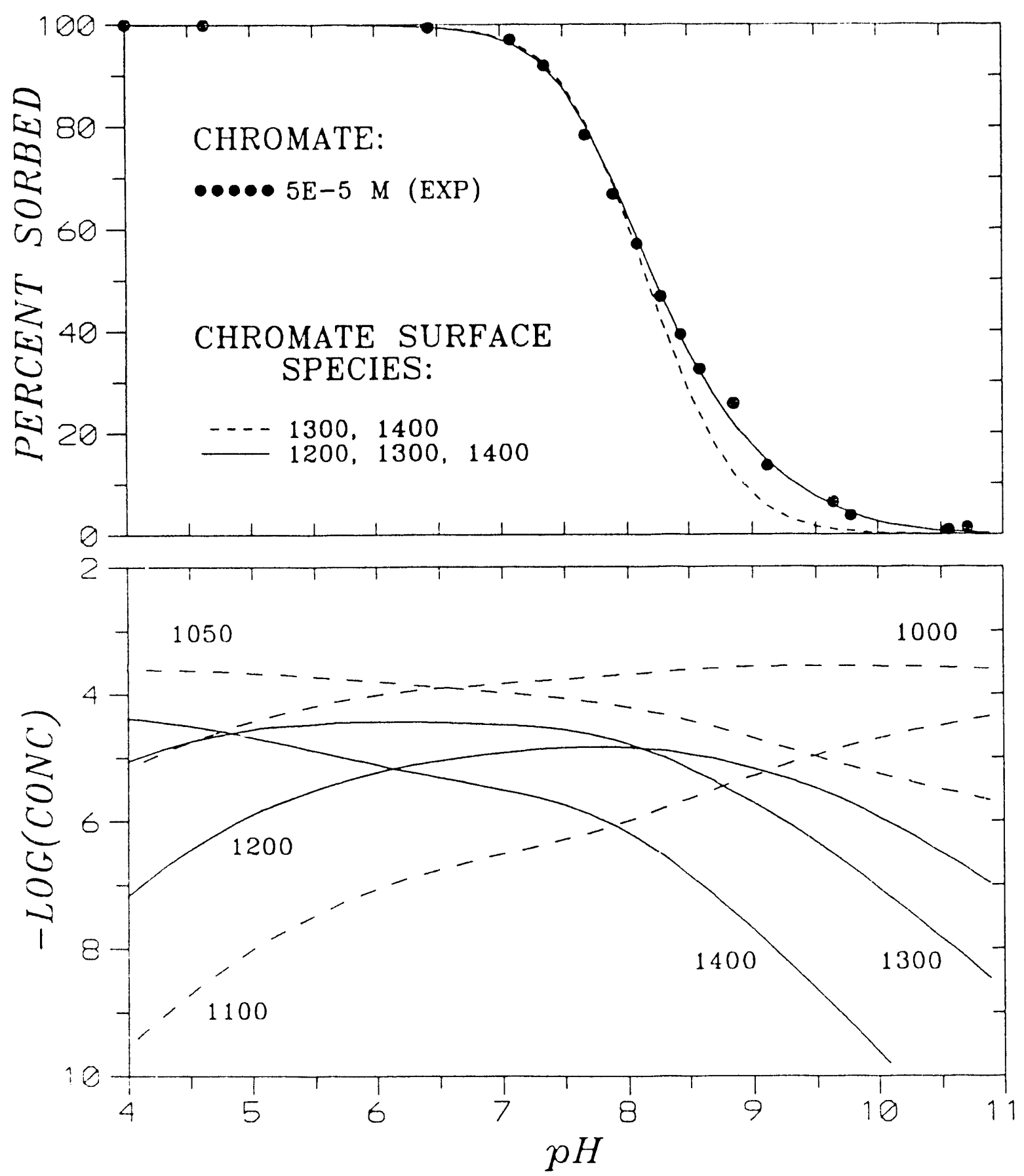

Figure 1.

Adsorption of chromate to goethite as a function of solution $\mathrm{pH}$ ("pH adsorption edge"). Solid line and dashed lines are two attempts at modeling, using two different assumed sets of active surface species. The species numbers and associated reactions are identified in Table 1 . The lower plot indicates the equilbrium distribution of species as predicted by the DLM. 
100

$\left[\mathrm{OH}^{-}\right]=\left[\mathrm{H}^{+}\right]^{-1} K_{100}^{\circ}\left(\gamma_{1}\right)^{-2}$

250

$$
\left[\mathrm{HA}^{-}\right]=\left[\mathrm{A}^{2-}\right]\left[\mathrm{H}^{+}\right] \quad K_{250}^{\circ} \gamma_{2}
$$

300

$$
\left[\mathrm{H}_{2} \mathrm{~A}\right]=\left[\mathrm{A}^{2-}\right]\left[\mathrm{H}^{+}\right]^{2} K_{300}^{\circ}\left(\boldsymbol{\gamma}_{1}\right)^{2}
$$

1050

$$
\left[\equiv \mathrm{SOH}_{2}^{+}\right]=\left[\equiv \mathrm{SOH}^{\circ}\right]\left[\mathrm{H}^{+}\right] \exp \left(-\mathrm{F} \psi_{0} / \mathrm{RT}\right)\left(K_{1050}^{\circ}\right)^{-1} \gamma_{1}
$$

1100

$$
\left[\equiv \mathrm{SO}^{-}\right]=\left[\equiv \mathrm{SOH}^{\circ}\right]\left[\mathrm{H}^{+}\right]^{-1} \exp \left(\mathrm{F} \psi_{0} / \mathrm{RT}\right) K_{1100}^{\circ}\left(\gamma_{1}\right)^{-1}
$$

1200

$$
\left[\equiv \mathrm{SOHA}^{2-}\right]=\left[\equiv \mathrm{SOH}^{\circ}\right] \quad\left[\mathrm{A}^{2-}\right] \exp \left(2 \mathrm{~F} \psi_{0} / \mathrm{RT}\right) \quad K_{1200}^{\circ} \gamma_{2}
$$

1300

$$
\left[\equiv \mathrm{SA}^{-}\right]=\left[\equiv \mathrm{SOH}^{\circ}\right] \quad\left[\mathrm{A}^{2-}\right]\left[\mathrm{H}^{+}\right] \exp \left(\mathrm{F} \psi_{0} / \mathrm{RT}\right) \quad K_{1300}^{\circ} \gamma_{2} \gamma_{1}
$$

1400

$\left[\equiv \mathrm{SAH}^{\circ}\right]=\left[\begin{array}{llllll}\equiv \mathrm{SOH}^{\circ} & {\left[\mathrm{A}^{2-}\right]} & {\left[\mathrm{H}^{+}\right]^{2}} & K_{1400}^{\circ} & \gamma_{2} & \left(\gamma_{1}\right)^{2}\end{array}\right.$

1500

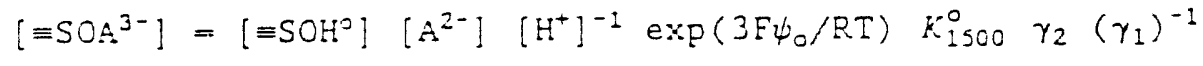

Table 1.

Reactions specified for use in fittine the experimental adsorption data in a diffuse layer surface complexation model (DLM). The species numbers correspond to the labels in the accompanying figures, and are the numbers assigned in the daza-ficting program EITEQL. 


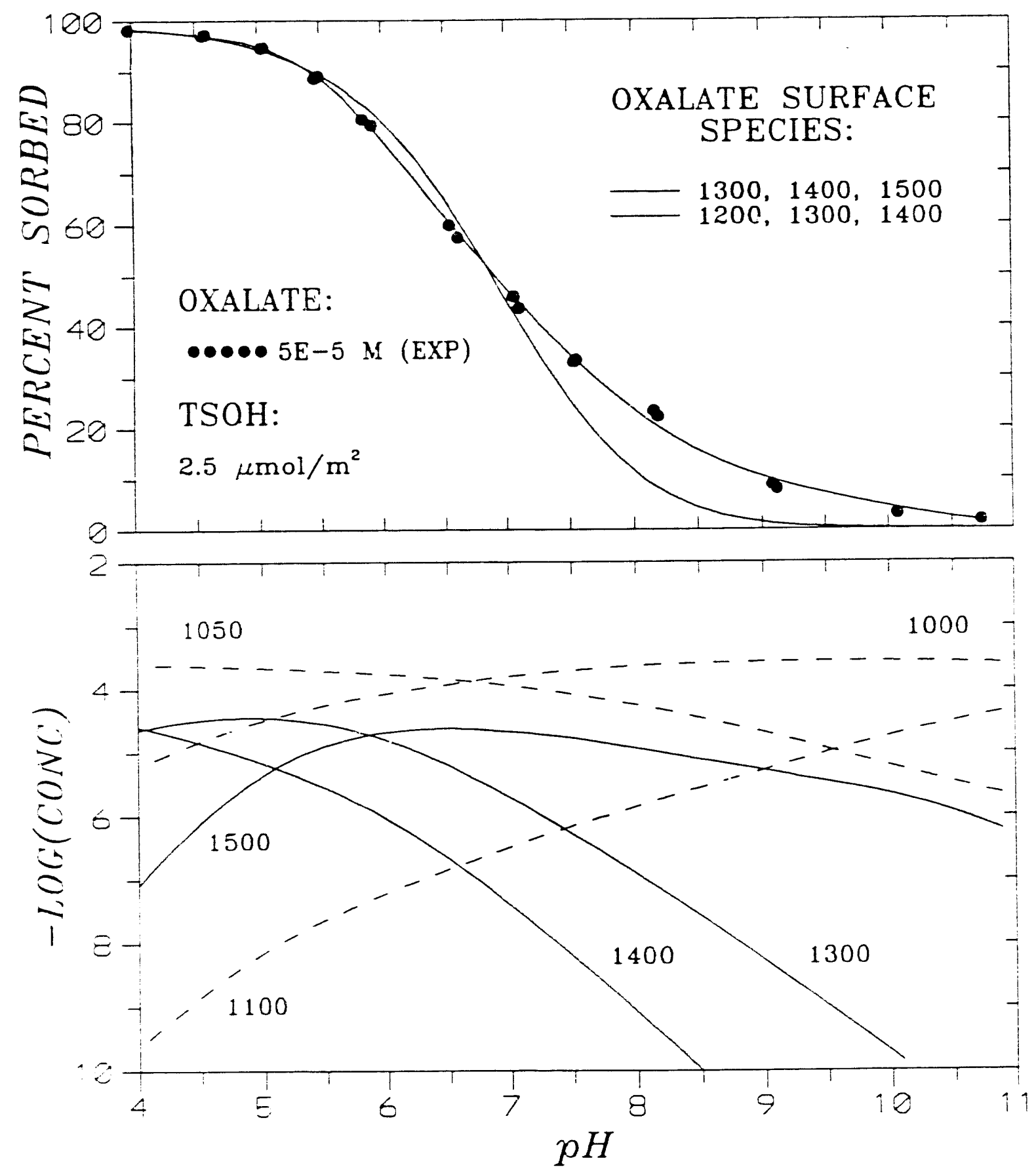

Figure 2 .

Adsorption of oxalate to goethite as a function of solution pH ("pH adsorption edge"). Lines represent two attempts at modeling, using two different assumed sets of active surface species. The species numbers and associated reactions are identified in Table 1 . The lower plot indicates the equilbrium distribution of species as predicted by the DLM. 


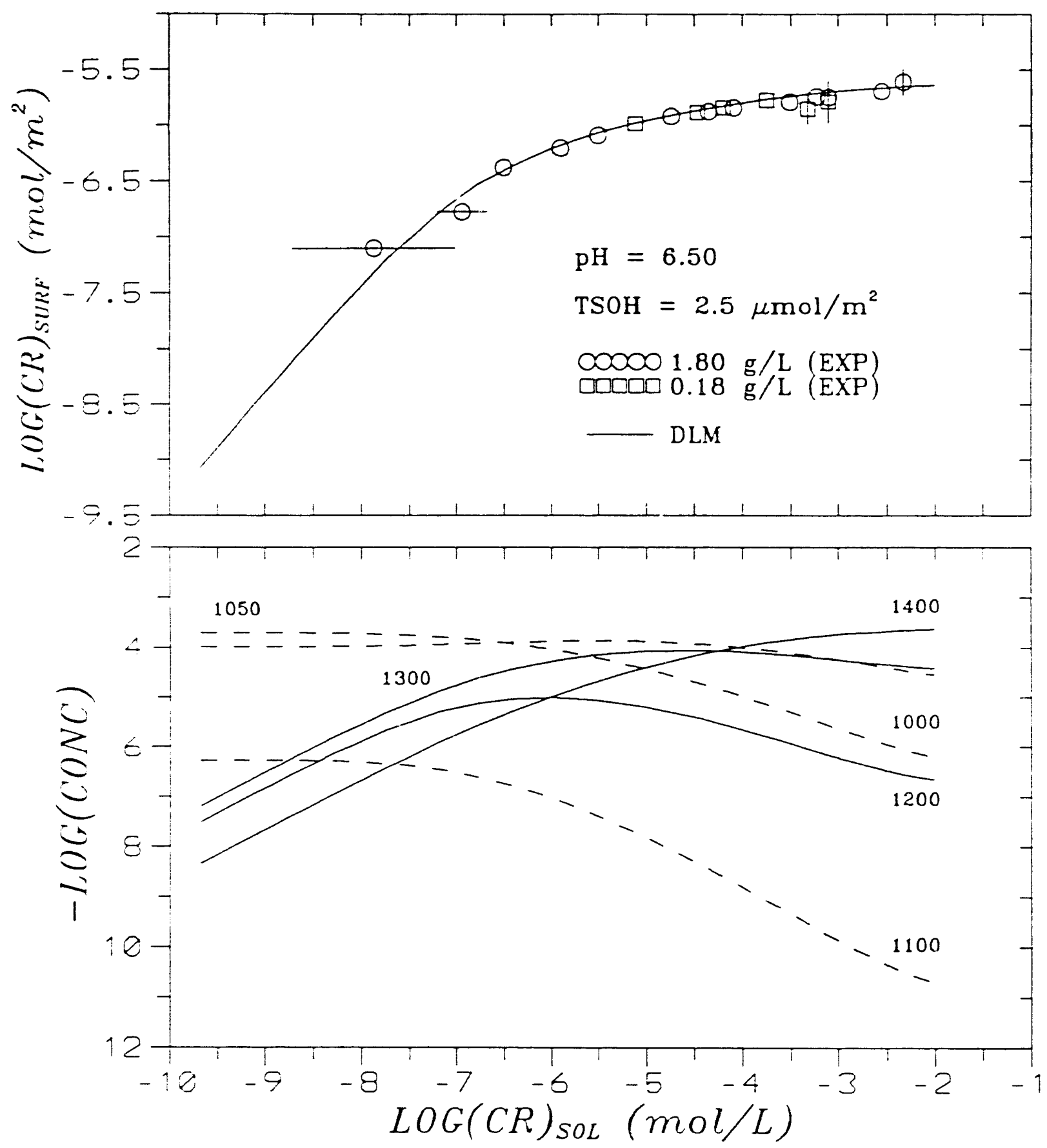

Figure 3.

Adsorption of chromate to goethite as a function of solution concentration of chromate (adsorption isotherm). Solid line indicates the DLM-computed fit of the data. The lower plot indicates the equilbrium distribution of species as predicted by the DLM. 


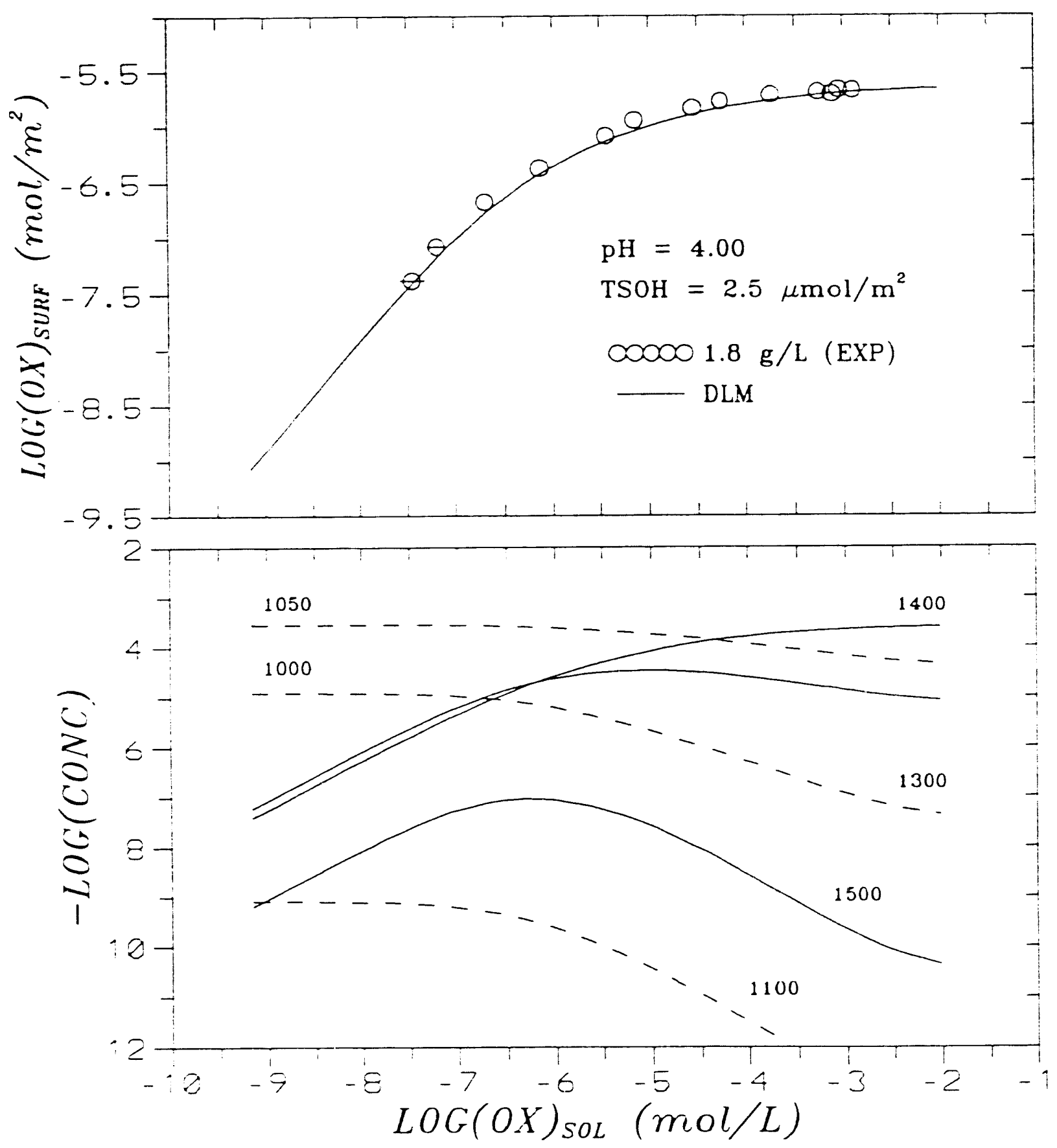

Eigure 4.

Adsorption of oxalate to goethite as a function of solution concentration of chromate (adsorption isotherm). Solid line indicates the DLM-computed fit of the cata. The lower plot indicates the equilbrium distribution of species as predicted by the DLM. 


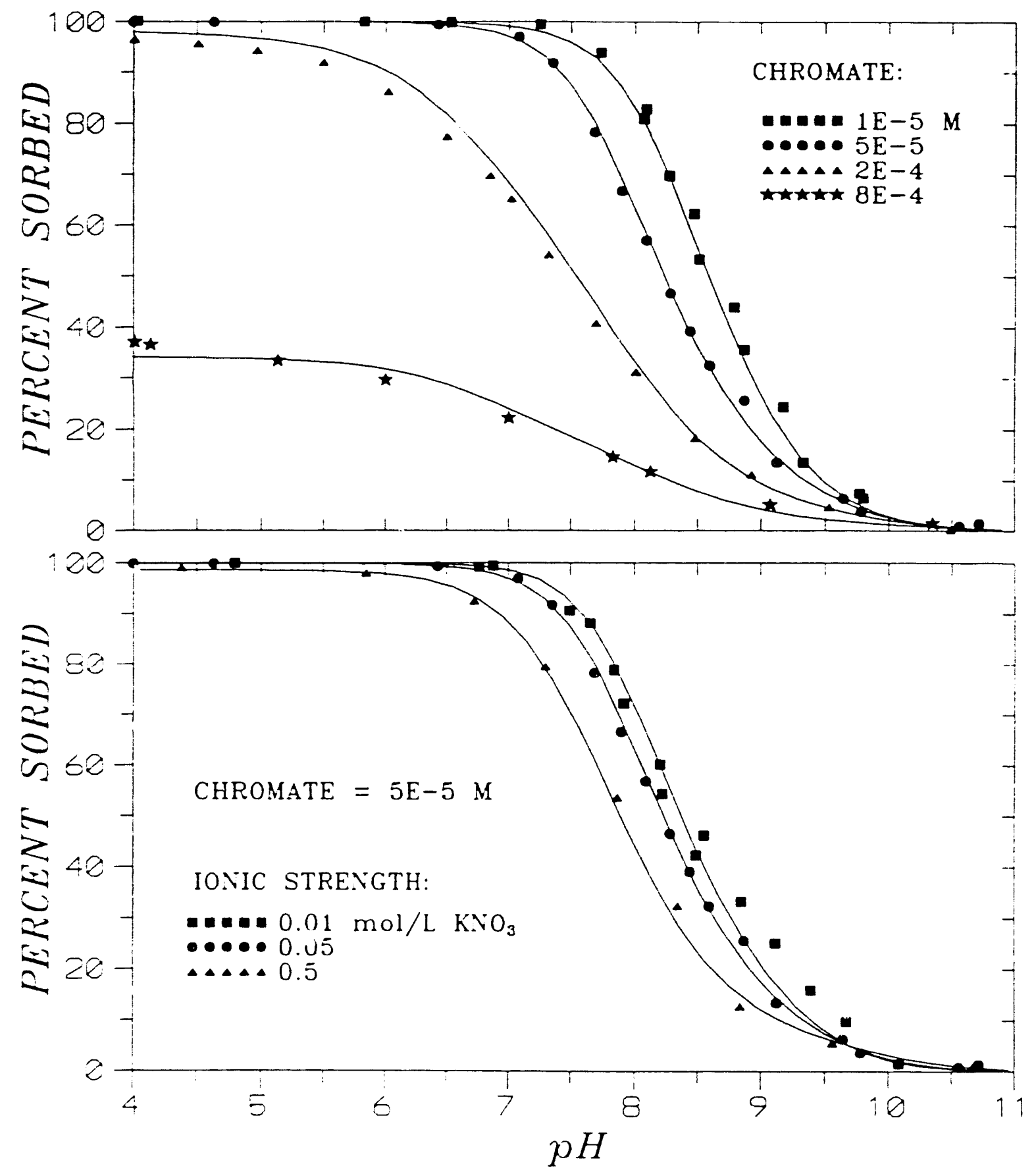

Figure 5.

(a) Adsorption pH edges of chromate as a function of increasing chromate in solution (b) Adsorption $\mathrm{pH}$ edges of chromate as a function of solution ionic strength. Solid lines indicate the DLM-computed fit of the data. 

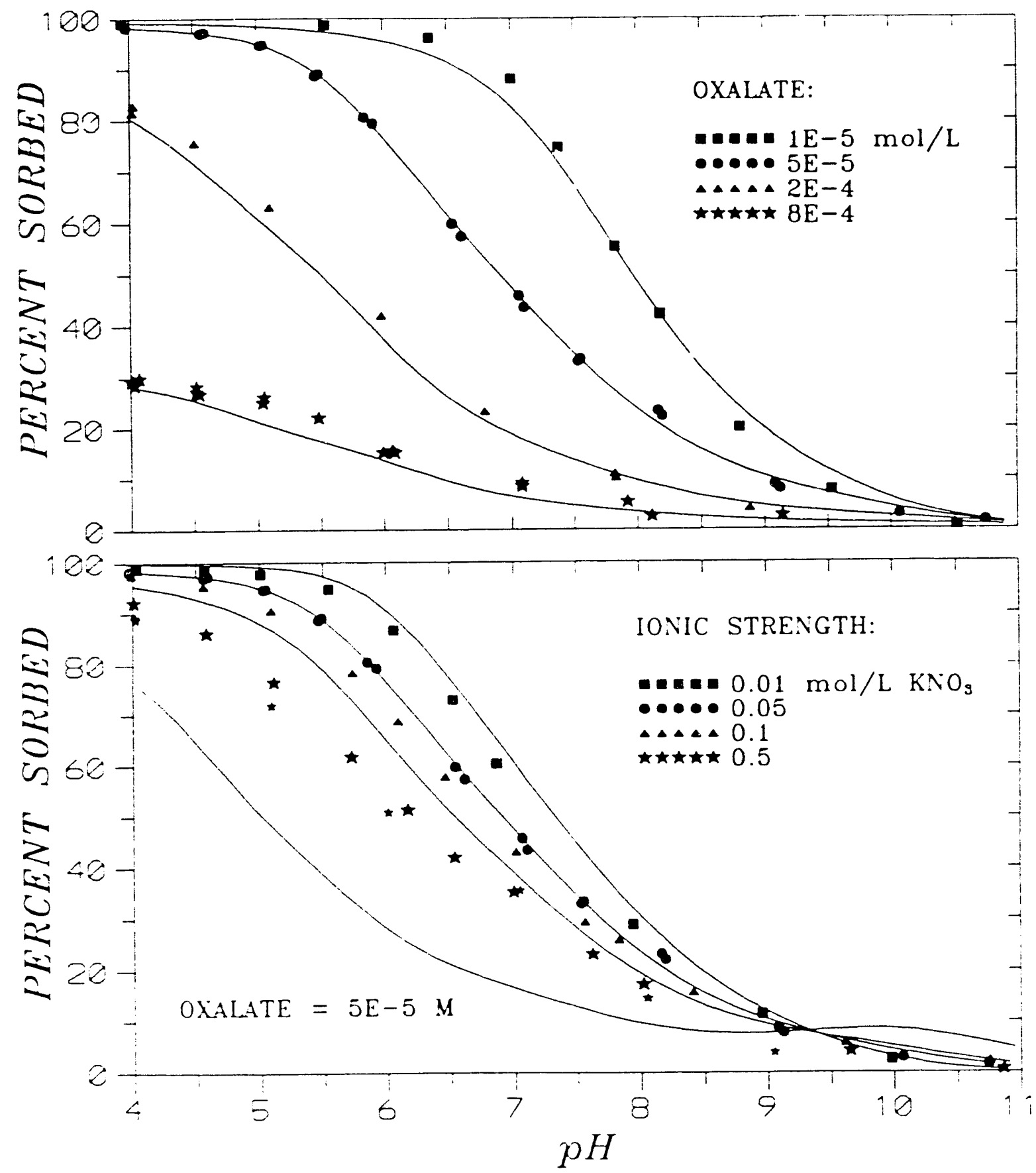

Figure 6.

(a) Adsorption $\mathrm{pH}$ edges of oxalate as a function of increasing oxalate in solution (b) Adsorption $\mathrm{pH}$ edges of oxalate as a function of solution ionic strength. Solid lines indicate the DLM-computed fit of the data. 

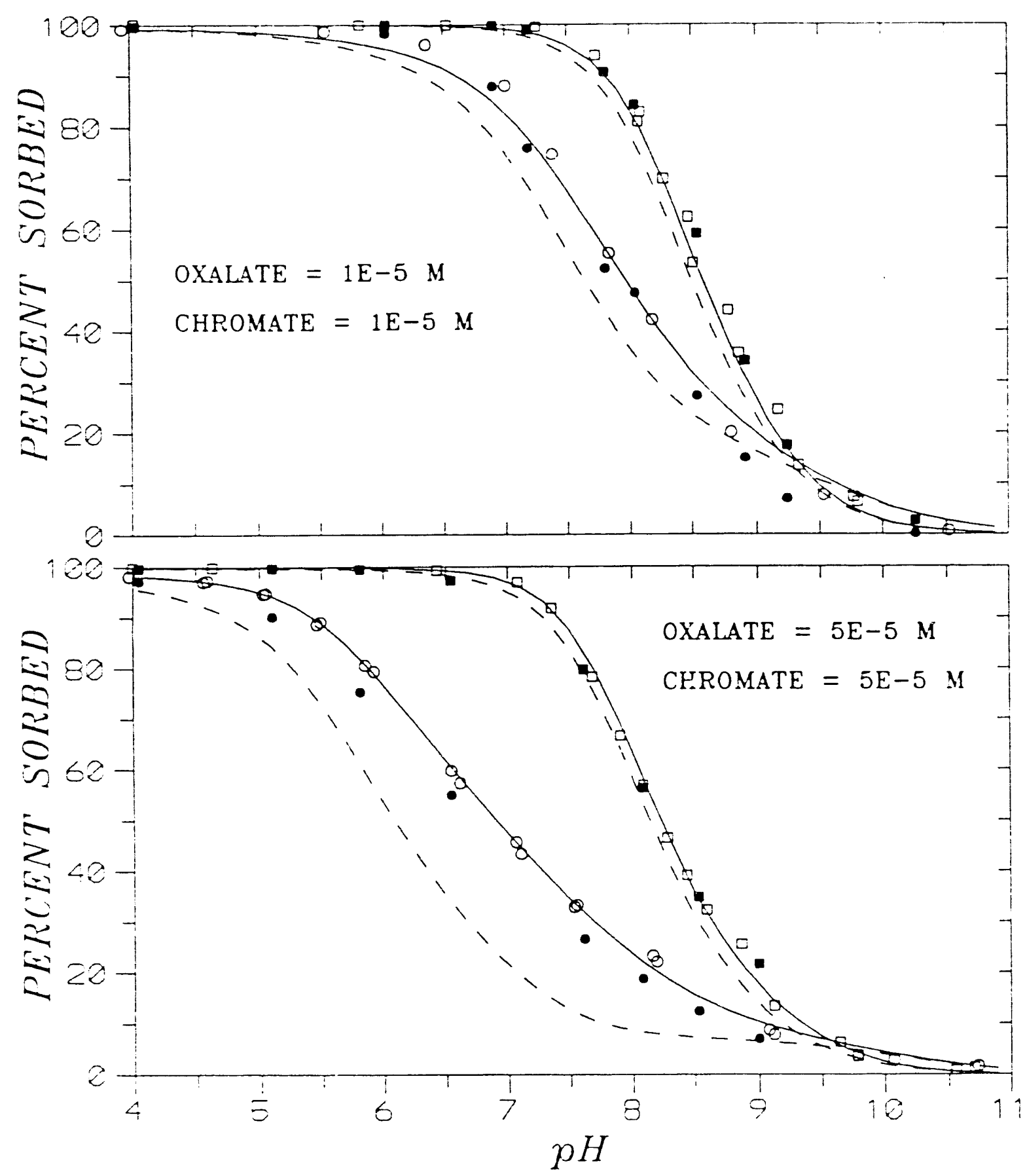

Figure 7 .

Adsorption $\mathrm{pH}$ edges of chromate and oxalate in single-adsorbate (no competition; open symbols) and binary-adsorbate (competing anions; filled symbols). Lines indicate the DLM-computed fit of the data. (a) 0 xalate $=10$ uM, chromate $=10$ 4: (b) Oxalate $=50$ uM, chromate $=50$ uM. 

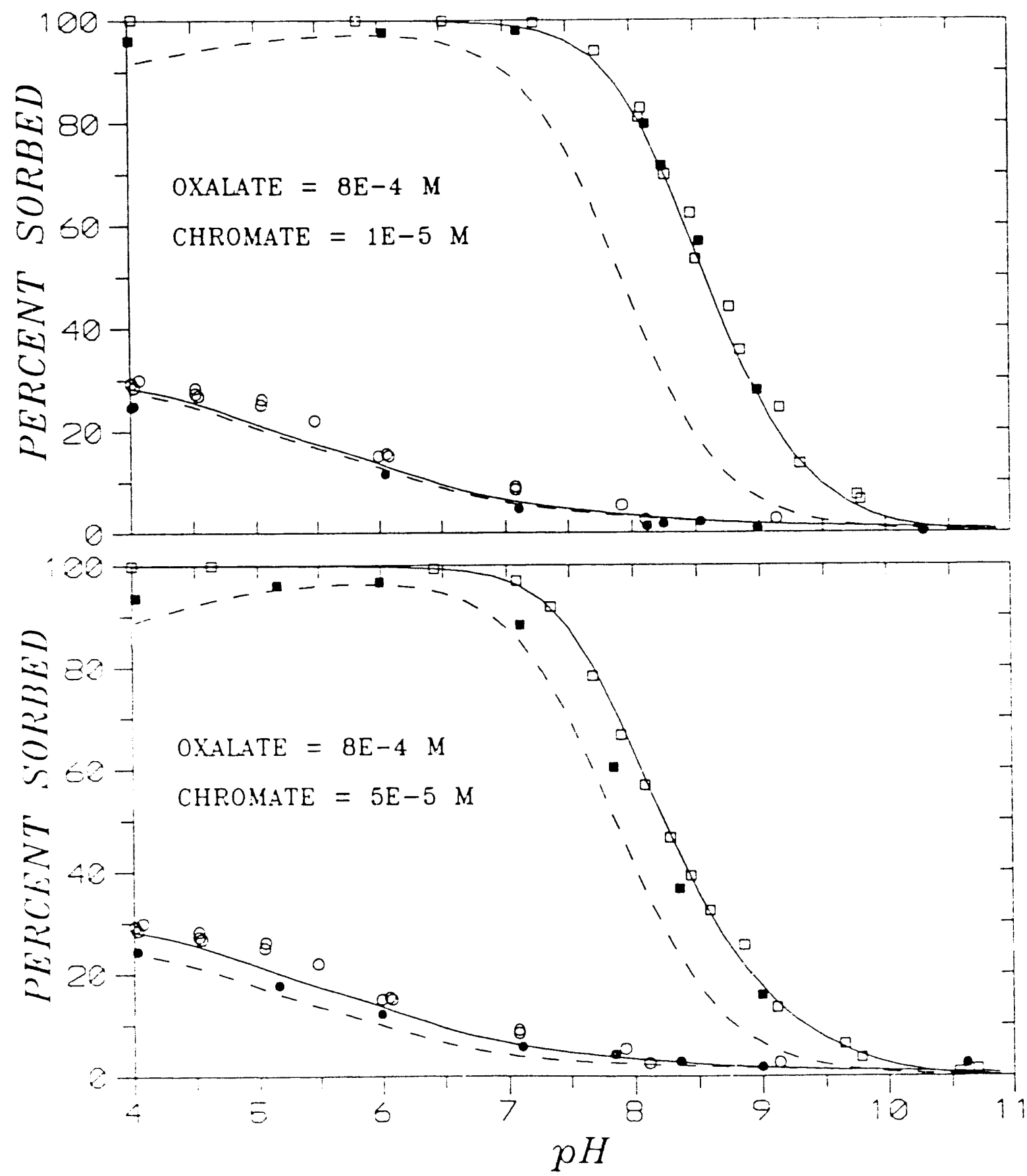

Fizune \&.

Asorption pH edges of chromate and oxalate in single-adsorbate (no competition; ope: s:mbols) and binary-adscrbate (competing anions: filled symbols). Lines aticate the DLM-computed fit of the data. (a) Oxalate $=800$ uy, chiomate $=10$ (4) axalate $=800$ uM, chromate $=50$ uM. 


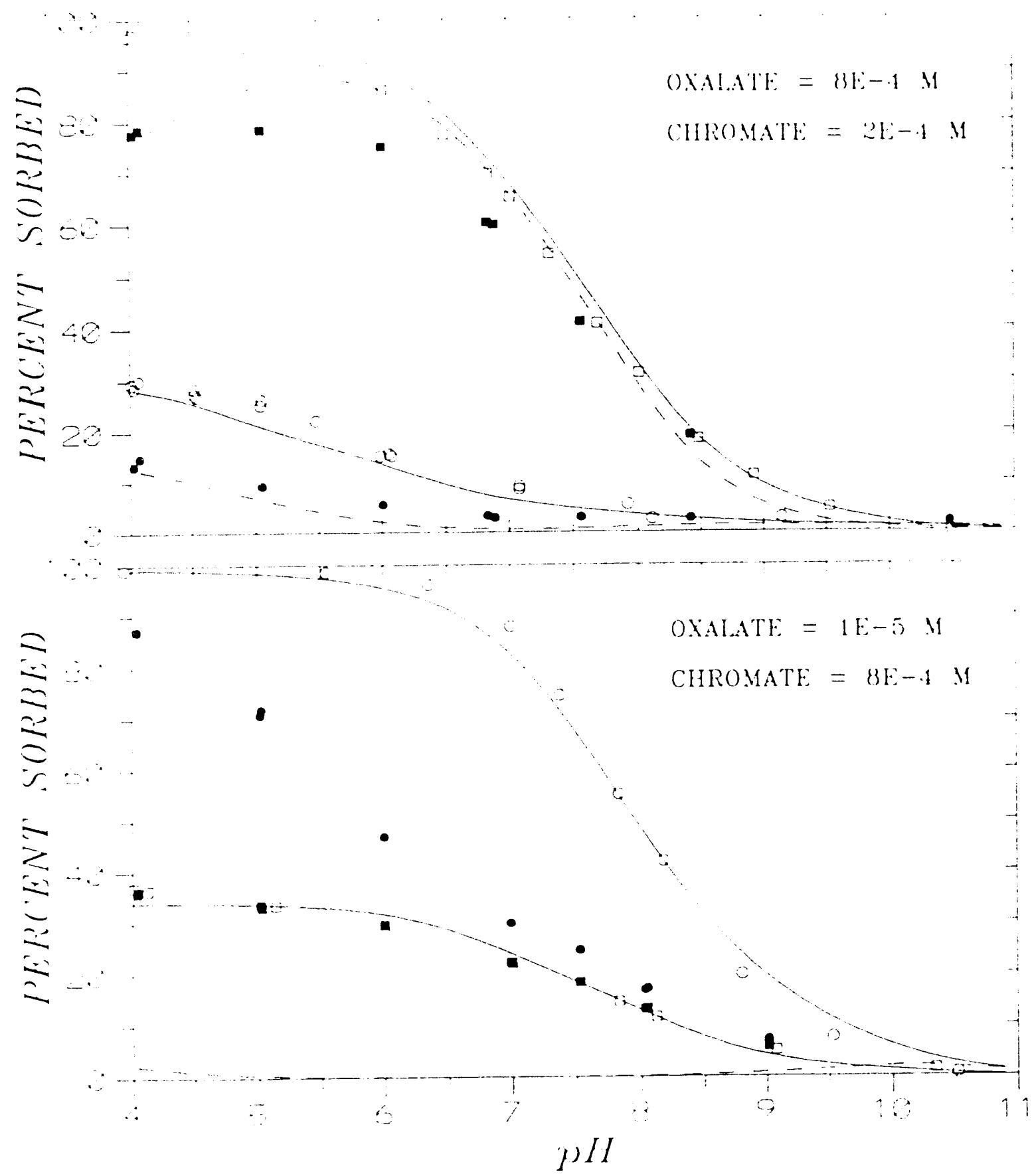

Figure 9.

Adsorption $\mathrm{pH}$ edges of chromate and oxalate in single-adsorbate (no competition; open symbols) and binary-adsorbate (competing anions; filled symbols). Lines indicate the DLM-computed fit of the data. (a) Oxalate $=800 \mathrm{uM}$, chromate $=200$ uM; (b) Oxalate $=10 \mathrm{uM}$, chromate $=800 \mathrm{uM}$. 


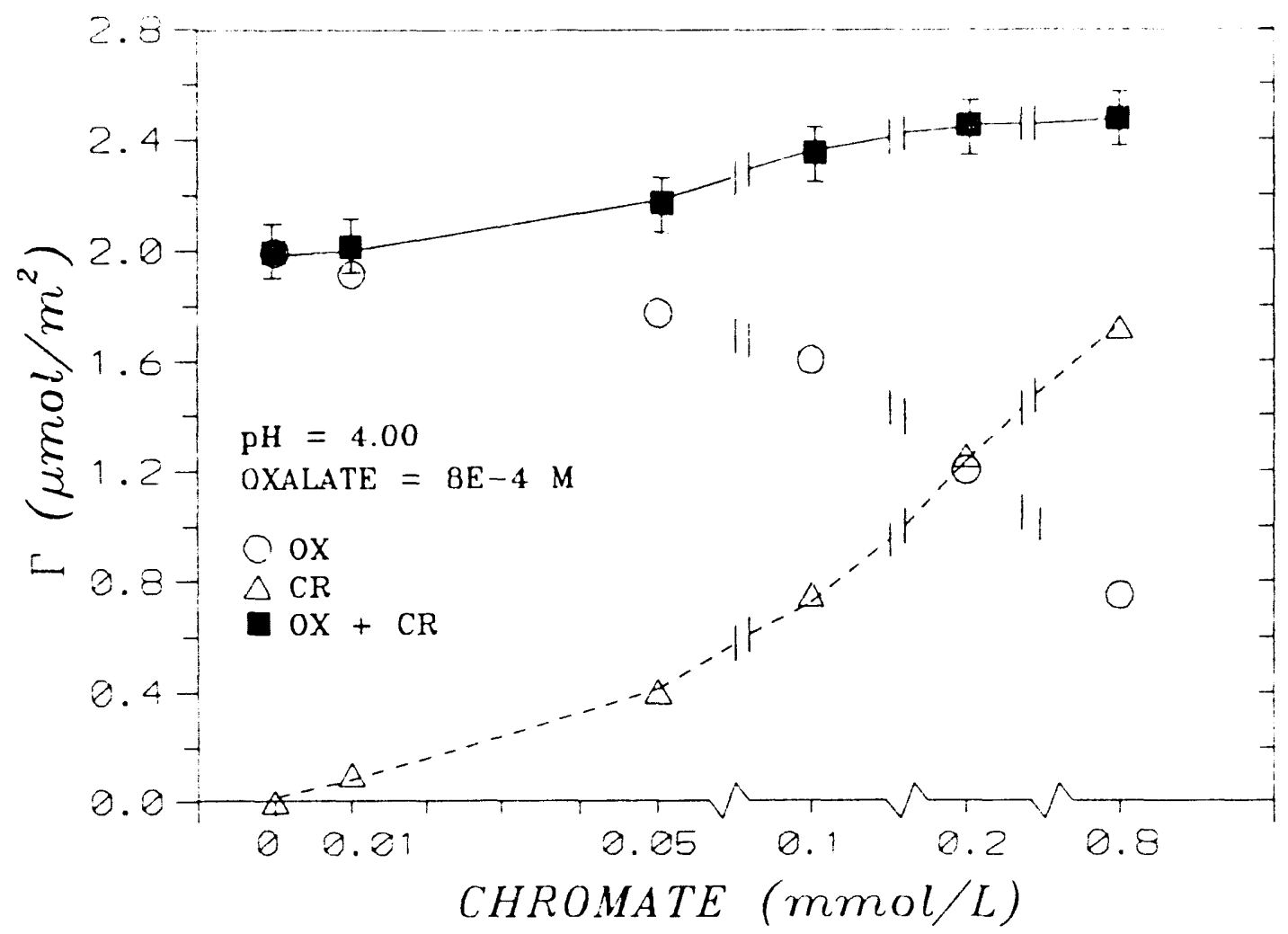

Figure 10.

Total amount of either oxalate or chromate adsorbed in a binary-adsorbate system as a function of increasing concentration of chromate in solution. The solid squares indicate the sum of the adsorbed concentrations of chromate and oxalate. 


\section{LIGAND-PROMOTED DISSOLUTION}
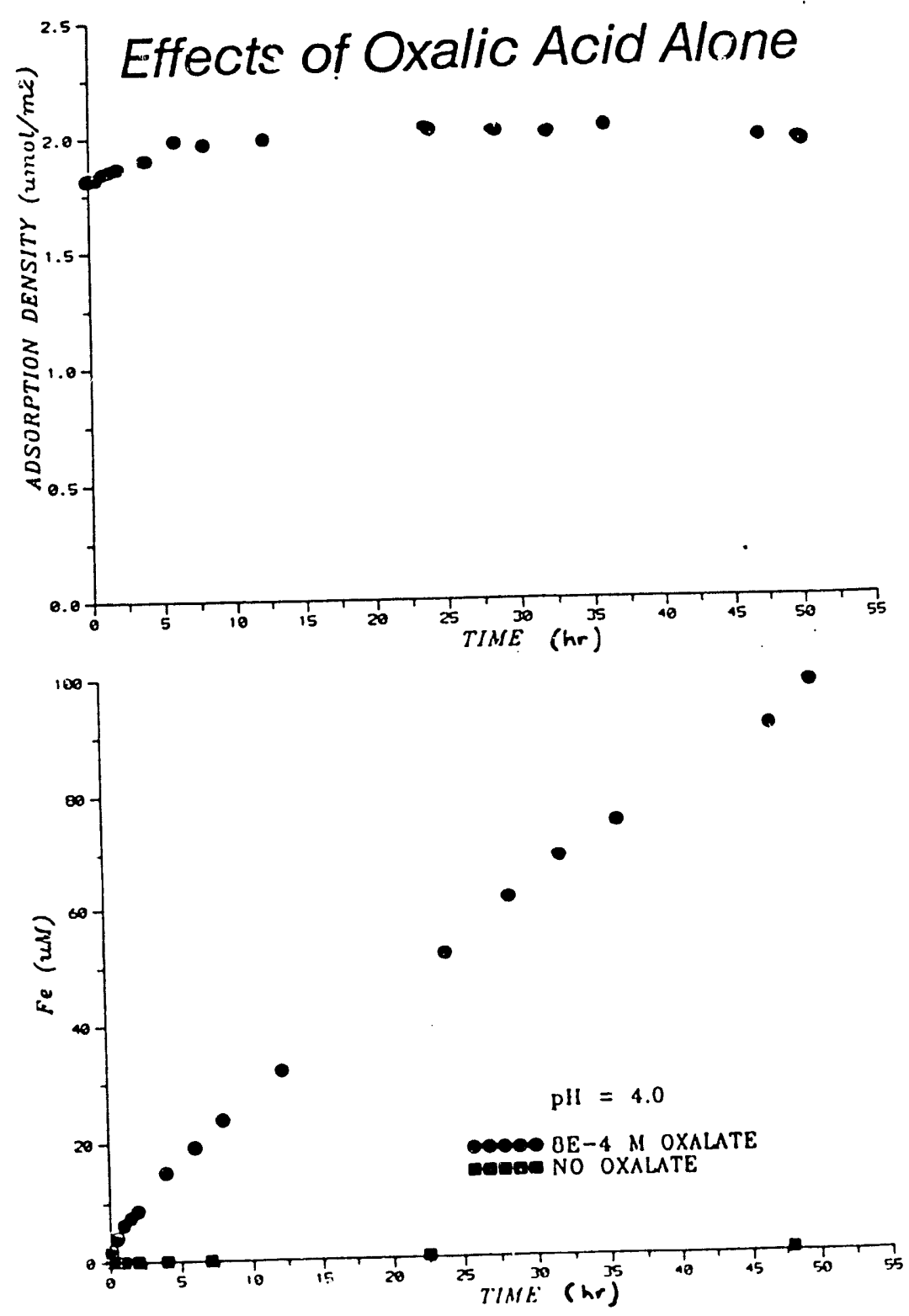

Figure 11.

Effect of adsorbed oxalate on the dissolution of goethite at $\mathrm{pH} 4$. (a) adsorption density of oxalate as a function of time during dissolution experiments; (b) cotal $\mathrm{Fe}$ in solution as a function of time for goethite in the presence and absence of $8 \times 10^{-4} \mathrm{M}$ oxalate. 


\section{LIGAND-PROMOTED DISSOLUTION}

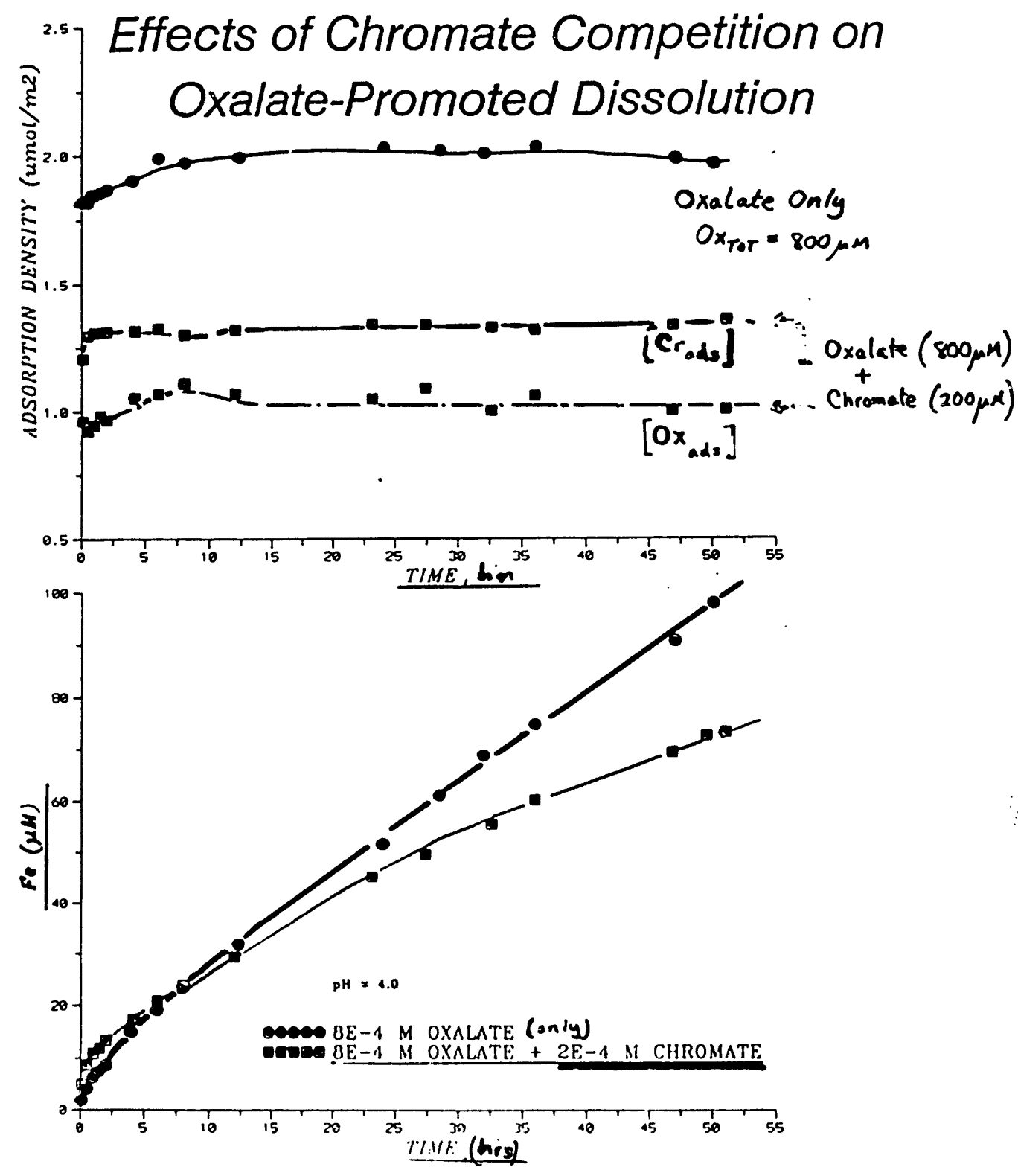

Figure 12 .

Effect of competition from chromate on adsorbed oxalate and corresponding dissolution of goethite at $\mathrm{pH}$ 4. (a) adsorption density of oxalate, and oxalate and chromate, as a function of time during dissolution experiments; (b) total $\mathrm{Fe}$ in solution as a function of time for goethite in the presence $8 \times 10^{-4} \mathrm{M}$ oxalate, with and without the addition of $2 \times 10^{-4} \mathrm{M}$ chromate. 
To this point in the project we have worked primarily with well defined oxide minerals in order to place the modeling and the theoretical development of anion competition into the clearest and least ambiguous experimental framework. In the final six months of the project we will complete our proposed work plan by extending this research into natural aquifer materials.

Soil and subsurface materials taken from the Hanford reservation have been obtained by arrangement with DOE Co-Contaminant Subprogram researchers at Pacific Northwest Laboratories (PNL). Chromate and oxalic acid adsorption will be quantified with batch techniques. The major mineral constituents of the samples will have been identified by PNL personnel as part of their development of the DOE site-materials sample library. Adsorption experiments will be conducted using whole-soil samples; the adsorptive properties of individual fractions will not be measured. We believe that the most efficient approach to whole-soil adsorption is to use literature data to specify the most reactive phases among the constitutents identified by PNL. The adsorption empirically observed for the bulk material can then be compared with model predictions based on hypothetical combinations of sites. These site combinations will not be fitted in a purely empirical way, but will be specified on the basis of the mineralogical composition of the soil sample. The research focus therefore will be placed on treating soils as heterogeneous mixtures with certain classes of active surfaces. We intend to extend our expertise in characterizing and modeling soil humates to DOE soil samples.

To supplement the surface complexation modeling we have used to this point, we are planning to explore alternate representations of heterogeneous adsorptive media. In particular, three recent models of humate-metal binding proposed by Van Rijmsdyk. Buffle, and Tipping appear to have many fratures in common, and all appear to offer some advantages in modeling highly heterogeneous adsorption phenomena. We will explore the utility of these models in interpreting our results, and will study the general suitability of such models for the modelling of complex, multicomponent, subsurface adsorption problems. 
APPENDIX

VARIABILITY IN THE MEASUREMENT OF HUMIC CARBONYL CONTENT

rumored and cycled eppantely -

22 

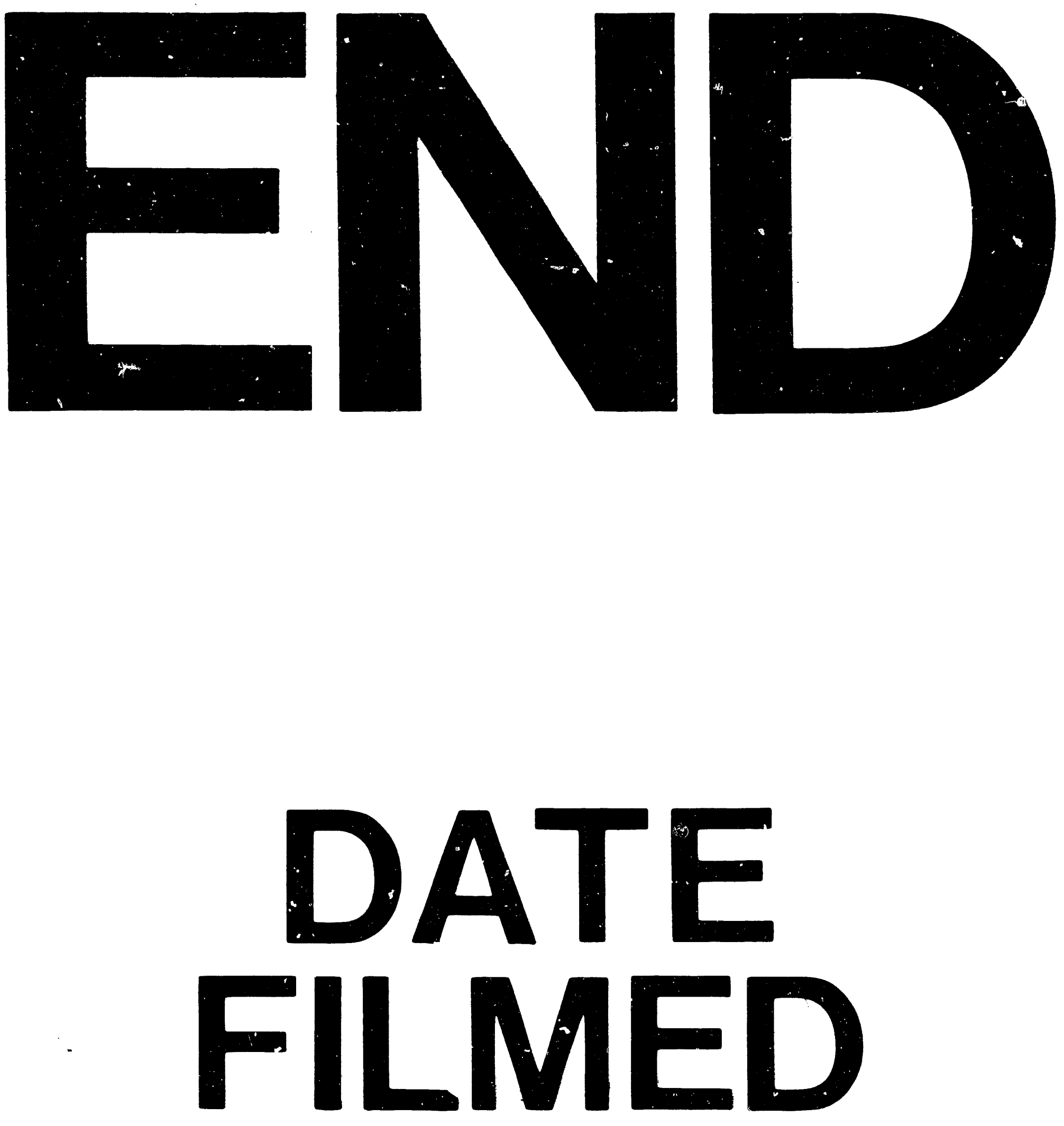

1

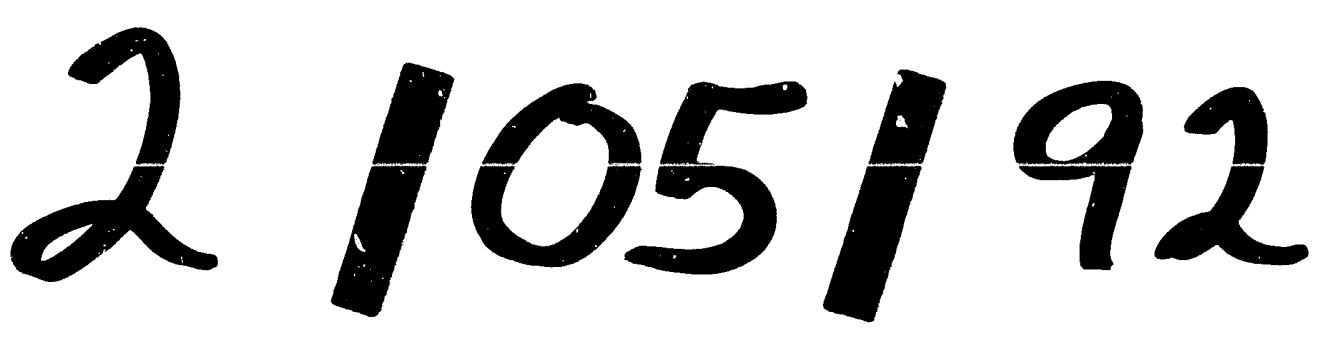


